Check for updates

Kent

Cite this as: $B M J 2022 ; 376: 0163$ http://dx.doi.org/10.1136/bmj.0163 Published: 20 January 2022

\title{
Covid-19: England prepares to ease plan B restrictions
}

\section{Jacqui Wise}

Plan B restrictions in England, including mandatory face masks and advice to work from home, will end from 27 January, the prime minister, Boris Johnson, has announced.

But as levels of infection remain high and the NHS is still under extreme pressure, health organisations have warned that the planned changes have not been guided by data.

Face masks will no longer be mandatory on public transport or in shops, and this requirement has been dropped immediately for secondary school pupils in classrooms. However, people are still advised to wear face coverings in closed or crowded spaces, particularly if coming into contact with people they do not normally meet.

There will be no requirement to show covid passes to attend certain events, although organisations will be allowed to use them if they choose. The guidance to work from home will end immediately, and restrictions on visits to care homes will also be relaxed in the coming weeks.

There will still be a legal requirement for people to self-isolate if they test positive for covid-19. However, Johnson told the Commons that there would "soon be a time" when self-isolation guidance could be removed entirely. The self-isolation rules expire on 24 March, and the prime minister said that he did not expect to renew them.

\section{Booster success}

Johnson told MPs that the success of the vaccine booster campaign, together with how the public had responded to plan $B$ measures, meant that the country could now return to plan A. He said that scientists believed it likely that the omicron wave had now peaked nationally and that hospital admissions had stabilised.

The latest survey by the Office for National Statistics estimated that in the week ending 15 January just under 3.5 million people in the UK had covid-19, down from 4.3 million the previous week. This equates to around one in 20 people. ${ }^{1}$ Covid-19 infections decreased in all regions in the most recent week except in the north east and the south west, where the trend was uncertain.

The plan B measures were brought in to curb the omicron wave before Christmas. Speaking at a press conference, England's health secretary, Sajid Javid, said, "This plan has worked, and the data shows omicron is in retreat."

He said that hospital admissions had fallen and that patient numbers in intensive care were at the same levels as last July. Laying out the new plans, he said that the government was looking to replace legal requirements on self-isolation with guidance and advice. He added that the government would soon set out plans to reduce restrictions on people visiting care homes.

\section{Risk of rebound}

The BMA council chair, Chaand Nagpaul, said that the government's decision risked creating a false sense of security when levels of infection and illness remained high and the NHS was still under crippling pressure.

"This decision clearly is not guided by the data," he said. "When plan B was introduced in December there were 7373 patients in hospital in the UK; the latest data this week shows there are 18 979. Case numbers too are nearly twice as many." He added that removing all restrictions would risk a rebound in the number of infections and would inevitably increase hospital admission rates.

Matthew Taylor, chief executive of the NHS Confederation, also warned that the NHS was under significant pressure and urged the government to be honest with the public that a decision to lift restrictions was a trade-off. He said, "We will have greater freedoms, but the cost-at least in the short term-will be that more people are likely to get sick with covid and that the health service will continue to have to deal with the extra burdens that this creates."

Saffron Cordery, deputy chief executive of NHS Providers, highlighted regional variation in the number of hospital admissions for covid-19, as numbers were increasing in the north east and Yorkshire but decreasing in London.

"This means that some trusts tell us they are expecting their peak later this week or possibly early next," she said. "There are also indications that it takes longer for hospitalisations to reduce than infection rates. That's why it's important that there is recognition that this surge isn't over and that the health service is still operating under extremely challenging circumstances."

\section{Scotland and Wales}

Scotland had already announced the end of many covid-19 restrictions, with nightclubs reopening and social distancing rules to be dropped from 24 January. However, people are still being asked to work from home, and measures such as face coverings on public transport and indoor public places will remain.

Wales had also already announced the easing of restrictions over the next two weeks, with crowds allowed to return to sporting events and nightclubs reopening.

Responding to Johnson's announcement, the Labour leader, Keir Starmer, said that he would support the relaxation of plan $B$ rules as long as science said that 
it was safe, and he asked for the scientific evidence behind the decision to be released. He said that this would reassure people that Johnson was "acting to protect their health, not just his job."

Stephen Griffin, associate professor at the University of Leeds School of Medicine, said that he was "aghast at the haste in which restrictions are being dropped." He added, "Yes, it is clear that on a case-by-case basis our population is experiencing less severe outcomes to infection, particularly for vaccines, but the sheer scale of omicron infections means clinical impact remains considerable-it's simple maths, really."

And Lawrence Young, virologist and professor of molecular oncology at Warwick University, said, "Removing plan B measures in the face of extremely high levels of infection is a risk. With over 94000 cases reported yesterday, talk of an end to the pandemic is premature.

"Perhaps it would have been wiser to wait for another couple of weeks before removing the advice to work from home and the face coverings mandate. There's no guarantee that infection levels will continue to fall, and the NHS remains under extreme pressure.”

1 Office for National Statistics. Coronavirus (COVID-19) Infection Survey headline results, UK: 19 January 2022. 19Jan 2022. https://www.ons.gov.uk/peoplepopulationandcommunity/healthandsocialcare/conditionsanddiseases/bulletins/coronaviruscovid19infectionsurveypilot/19january2022

This article is made freely available for personal use in accordance with BMJ's website terms and conditions for the duration of the covid-19 pandemic or until otherwise determined by BMJ. You may download and print the article for any lawful, non-commercial purpose (including text and data mining) provided that all copyright notices and trade marks are retained. 